\title{
A study of a karate trial teaching class in a teacher training course - based on students' formative assessment
}

\author{
Kentaro TAI ${ }^{*}$, Shutaro JINNO2 ${ }^{2}$, Namika MOTOSHIMA ${ }^{2}$, Toshiyuki MIYARA ${ }^{2}$, Takeru SHIMA ${ }^{1}$, \\ Miki SUETSUGU $^{3}$, Masaki FUMOTO ${ }^{4}$, \& Hiroyuki IMAMURA ${ }^{2}$ \\ ${ }^{1}$ Gunma University (Japan) \\ ${ }^{2}$ Nagasaki International University (Japan) \\ ${ }^{3}$ Komazawa University (Japan) \\ ${ }^{4}$ Tokyo International University (Japan)
}

8th IMACSSS International Conference Abstracts, Viseu (Portugal), October 10-12, 2019

Type: Poster presentation

\begin{abstract}
The purpose of this study was to examine the effectiveness of a karate trial teaching class in an initial teacher training course, through students' formative assessment. It involved two case studies of trial teaching classes of karate and that of two other activities, taught by the students of an initial teacher training course. The results were assessed using the Students' Formative Assessment of Physical Education (P.E.) Classes scale. Results showed significant differences between groups in "New discovery" $(p<.05)$ and a trend toward statistical significance in "Skill growth", "Fun Exercise" and "Learning friendly" ( $p<.10)$ based on the classes provided by karate and other teaching materials. This implies that karate might have different acute effects on students' learning process in the context of school-level physical education.
\end{abstract}

Keywords: Martial arts; combat sports; karate; physical education; teacher education; formative assessment.

\section{Introduction}

In Japan, learning budo (martial arts) is compulsory in health and physical education classes starting from junior high up to the high school level (MEXT, 2008). At the junior high school level, all first and second graders are required to take budo classes as a way to inculcate the understanding of traditional culture. Several studies have suggested making karate-do a part of teaching material for school classes (Koyama, 2011; Imamura, 2012). However, in pedagogical research, there are few studies using class settings and students' assessment in physical education compared to those for other areas, and studies focused on pre-service teachers learning karate-do are even rarer.

\section{Objectives}

The purpose of this study was to examine the effects of two karate lessons in a sample of students of a physical education initial teacher education course.

\section{Methodology}

Table 1 shows the participants' characteristics. Those playing high school students' roles were all university students of a teacher training course who have already experienced high school students' roles in many simulated lessons. The students playing the teachers' role for the three contents were different, all third graders who had also experienced simulated classes more than twice. The participants took simulated lessons held at University ' $N$ ' in June 2019, aimed at training physical education teachers in junior high school under the perspective of formative assessment. The contents of the classes included (1) Volleyball: ball game, net type, (2) Karate: kumite, and (3) Mat exercise: gymnastics. 
Table1 the participants of the mock classes

\begin{tabular}{ccccc}
\hline $\begin{array}{c}\text { teaching materials } \\
\text { taecher's role }\end{array}$ & Grade & (1) volleyball & (2) Karate & (3)mat exercise \\
student's role & number & 22 (21yo) & 3rd (21yo) & 3rd (21yo) \\
& 4th Grade & 4 & 22 & 20 \\
& 3rd Grade & 6 & 5 & 4 \\
& 2nd Grade & 12 & 11 & 7 \\
& 1st Grade & 0 & 0 & 0 \\
\hline
\end{tabular}

At the end of each class, those who had taken the simulated lesson assessed it by using the Students' Formative Class Assessment Scale (Takahashi et al., 1994), modified from previous studies. This scale is composed of nine items and four factors, namely: "Outcome", "Motivation", "Ways of learning" and "Cooperation".

Two groups were considered: karate and volleyball/mat exercises. SPSS statistical software 25.0J (Chicago, IL) was used for data analysis. The descriptive statistics included means and standard deviation. Differences in the mean values of the karate class and the classes using other teaching materials were analyzed using a $t$-test. Two-sided $p<.05$ was considered to be statistically significant.

\section{Results}

Table 2 shows the result of the $t$-test. Significant differences were found in "New discovery", with karate group achieving higher scores, and a trend towards statistical significance was found in "Skill growth" (higher scores in karate group), and "Fun Exercise" and "Learning friendly" (volleyball/mat exercises achieving higher scores).

Table2 the results of Karate classes and other materials

\begin{tabular}{|c|c|c|c|c|c|c|c|c|c|c|c|c|}
\hline \multirow[b]{2}{*}{ Lower factor } & \multirow[b]{2}{*}{ Factor } & \multicolumn{3}{|c|}{ Whole $(N=64)$} & \multicolumn{3}{|c|}{ Karate $(N=22)$} & \multicolumn{3}{|c|}{ Other $(N=42)$} & \multirow{2}{*}{ t Value } & \multirow{2}{*}{$p$} \\
\hline & & $M$ & $S D$ & & $M$ & $S D$ & & $M$ & $S D$ & & & \\
\hline 1 Impressive experience & Outcome & 3.66 & 0.76 & ) & 3.73 & 0.70 & ) & 3.62 & 0.79 & ) & -0.54 & n.s. \\
\hline 2 Skill growth & Outcome & 3.83 & 0.79 & ) & 4.09 & $(0.75$ & ) & 3.69 & $(0.78$ & ) & -1.98 & t \\
\hline 3 New discovery & Outcome & 3.75 & 0.82 & ) & 4.05 & $(0.79$ & ) & 3.60 & $(0.80$ & ) & -2.15 & *: \\
\hline 4 Best exercise & Motivation & 4.64 & $(0.60$ & ) & 4.68 & 0.48 & ) & 4.62 & 0.66 & ) & -0.39 & n.s. \\
\hline 6 Voluntary learning & Ways of learning & 4.33 & $(0.80$ & ) & 4.14 & 0.89 & ) & 4.43 & 0.74 & ) & 1.40 & n.s. \\
\hline 7 Loarning with good faith & Ways of loarning & 3.78 & $(1.03$ & ) & 3.73 & $(1.12$ & ) & 3.81 & $(0.99$ & ) & 0.30 & n.s. \\
\hline 8 Learning friendly & Cooperation & 4.47 & 0.69 & ) & 4.23 & 0.87 & ) & 4.60 & 0.54 & ) & 1.81 & $*$ \\
\hline 9 Collaborative learning & Cooperation & 4.31 & $(0.79$ & ) & 4.09 & $(1.02$ & ) & 4.43 & $(0.63$ & ) & 1.64 & m.s. \\
\hline
\end{tabular}

\section{Discussion and Conclusion}

Kobayashi (2018) points out that for situations where physical strength and awareness of movement are polarized, karate may be an effective teaching material, making exercise a joy even for students who are not good at exercising. In our study, the karate lesson was highly evaluated under the three 'outcome' factors, although only differences on "skill growth" were significant. As all the students in the karate lesson experienced karate for the first time, it is assumed that they saw the outcome in terms of learning new physical movements and specific karate skills. For students with little experience in karate or martial arts, the acute effect of such lesson made them feel that their skills grew, compared to other exercises they had already experienced before such as volleyball or mat exercises. The results of the study thus suggest that karate classes in school-level physical education teacher education might have different acute effects on the perception of learning outcomes of students compared to other activities. Further studies should evaluate the effects of karate or martial arts lessons in longer periods of practice. 


\section{References}

Imamura, H., Yoshimura, Y., Iide, K., \& Tai, K. (2012). Karate as Physical Education: Aspect of Physical Fitness. Nagasaki International University Review, 12, 87-94.

Koyama, M. (2011). Educational Function of Karate-do. Tokyo: BAB Japan.

MEXT - Ministry of Education, Culture, Sports, Sciences and Technology. (2008). The Courses of Study for Secondary Schools - Physical education. Kyoto: Higashiyama Syobo.

Takahashi, T., Hasegawa, E., \& Kariya, S. (1994). Construction of an instrument for formative evaluation of physical education class. Japan Journal of Physical Education, Health and Sport Sciences, 39(1),29-37.

Kobayashi, Y., Hiraoka, H., Kiryu, S., Nabeyama, T., Fumoto, M., \& Ishikawa, Y. (2018). Budo image of university physical education students attending budo classes. Research Journal of Budo. 50(2),79-87. 